\title{
JOGOS DIGITAIS NA EDUCAÇÃO: POSSIBILIDADES PARA TEMAS GERADORES
}

\author{
DIGITAL GAMES IN EDUCATION: POSSIBILITIES FOR GENERATING THEMES
}

\author{
JUEGOS DIGITALES EN LA EDUCACIÓN: POSIBILIDADES PARA TEMAS \\ GENERADORES
}

REVISTA PEDAGÓGICA

Revista do Programa de Pós-graduação em Educação da Unochapecó | ISSN 1984-1566 Universidade Comunitária da Região de Chapecó | Chapecó-SC, Brasil Como referenciar este artigo: CIPRIANI, C.; EGGERT, E. Jogos digitais na educação: possibilidades para temas geradores. Revista Pedagógica, Chapecó, v. 19, n. 41, p. 242-254, maio./ago. DOI: http://dx.doi.org/10.22196/rp.v19i41.3293

\begin{abstract}
RESUMO: Faz pouco mais de 50 anos que os jogos digitais iniciaram sua trajetória pelo mundo. De fase em fase, afloram recheados de discussões e pormenores que merecem ser discutidos ao invés de negligenciados. Diante disso, o que nos propomos neste ensaio é pensar os jogos digitais na educação a partir das concepções de Paulo Freire - mais especificamente os jogos despontando como temas geradores. Para o melhor desenvolvimento da temática, partimos da seguinte pergunta-guia: os jogos digitais, enquanto linguagens, podem ser parte do processo maior para pensar os temas geradores, tal como outros pontos circunstancias da teoria de Paulo Freire? Nossos argumentos centralizamse em leituras freireanas, com aproximações ao pensamento pragmático norte americano. Na primeira parte do artigo, nós nos debruçamos sobre as questões dos temas geradores; na segunda parte, aproximamos discussões teóricas com a viabilidade de exemplos com games mercadológicos. Ao final, nos parece que os jogos digitais tomados como temas geradores são ferramentas desafiadoras à alfabetização funcional tecnológica.
\end{abstract}

Palavras-chave: Educação. Jogos Digitais. Temas Geradores. Tecnologia.

ABSTRACT: It was a little more than fifty years ago that digital games began their journey around the world. From phase to phase they emerge filled with discussions and details that deserve to be discussed rather than neglected. Therefore, what we propose in this paper is to think the digital games in education from freireans conceptions of Paulo Freire - specifically the games emerging with generating themes. For the best development of the subject, we start with the following guiding question: digital games, as languages, can be part of the larger process to think the generating themes, like other circunstancial points of Paulo Freire's theory?
Our arguments are centered on freireans readings with approaches to the north american pragmatic thinking. In the first part of the article we work through the issues of the generating themes, and in the second part, we approach theoretical discussions with the feasibility of examples with market games. At the end, it seems that digital games taken as generating themes are challenging tools to functional technological literacy.

Keywords: Education. Digital games. Generating Themes. Technology.

RESUMEN: Hace poco más de cincuenta años que los juegos digitales iniciaron su trayectoria por el mundo. De fase en fase aparecen rellenados de discusiones y pormenores que merecen ser discutidos al revés de neglicenciado. Delante eso, lo que nos proponemos en este ensayo es pensar los juegos digitales en la educación a partir de concepciones freireanas del teórico brasileño Paulo Freire - más específicamente los juegos surgiendo como temas generadores. Para el mejor desarrollo de la temática, empezamos por la siguiente pregunta-guión: ¿los juegos digitales, en cuanto lenguaje, pueden ser parte del proceso mayor para pensar los temas generadores, tal como otros puntos circunstanciales de la teoría de Paulo Freire? Nuestros argumentos se centralizan en lecturas freireanas, con aproximaciones al pensamiento pragmático norteamericano. En la primera parte del artículo se pone en relieve las cuestiones de los temas generadores, en la segunda parte, aproximamos discusiones teóricas con la factibilidad de ejemplos con juegos mercadológicos. Al final, nos parece que los juegos digitales tomados como temas generadores son herramientas desafiadoras a la alfabetización funcional tecnológica.

Palabras clave: Educación. Juegos Digitales. Temas Generadores. Tecnología. 
* Possui graduação em Curso de Publicidade e Propaganda pela Universidade Comunitária da Região de Chapecó (UNOCHAPECÓ) (2011) e mestrado em Educação, com bolsa integral da Fundação de Apoio à Pesquisa Científica e Tecnológica do Estado de Santa Catarina/Coordenação de Aperfeiçoamento de Pessoal de Nível Superior (Fapesc/Capes), pela mesma instituição (2015). É doutorando em Educação na Escola de Humanidades da Pontifícia Universidade Católica do Rio Grande do Sul (PUC-RS) e bolsista integral CAPES/PROEX. Tem experiência em: educomunicação, design crítico, filosofia latina e filosofia da educação.

** Pós-Doutorado (CNPq), no Programa de Estudios de la Mujer da Universidad Autónoma Metropolitana de Xochimilco (UAM-X). Doutora em Teologia pela Escola Superior de Teologia (1998). Mestrado em Educação pela Universidade Federal do Rio Grande do Sul (1992). Professora adjunta da Escola de Humanidades e atual coordenadora do Programa de Pós-Graduação em Educação (PPGEdu) da Pontifícia Universidade Católica do Rio Grande do Sul (PUC-RS).

1 Para este ensaio, o marco zero dos Jogos Digitais são as experiências interativas Mouse in the Maze e Tic-Tac-Toe - de 1960 para computador TX-o. Segundo Gularte (2010), esses aparatos utilizavam todas as características de um jogo eletrônico, enquanto dispositivo e representação subjetiva. Cabe também lembrar que os termos jogos digitais, jogos eletrônicos, games e videogames são usados neste trabalho como sinônimos.

2 Em pesquisa de 2013, estimou-se que existiam 230 milhões de celulares para uma população aproximada de 200 milhões. Segundo Arruda (2014), é possível deduzir que a maioria das pessoas jogou ou joga algum tipo de jogo eletrônico. Ver também: Olhar digital, 2011.

\section{INTRODUÇÃO}

A história dos jogos digitais pelo mundo tem pouco mais de 50 anos ${ }^{1}$. De década em década, ela aflora recheada de discussões, curiosidades, apontamentos e pormenores que precisam ser aprendidos e pensados ao invés de negligenciados, visto que, segundo Arruda (2009), os jovens passam mais tempo em frente ao computador ou ao videogame do que no ambiente escolar.

Assim, o que pretendemos neste ensaio é pensar os jogos digitais na Educação a partir de concepções freireanas enquanto temas geradores. Para propor tal assunto, partimos de uma premissa mais ampla, a saber: a irreversibilidade do processo imersivo de nossa vivência - humana, animal, vegetal, social - em um mundo cada vez mais tecnológico (VIEIRA PINTO, 2005a, 2005b). Se no meio mercadológico e cultural do século XXI já é possível observar uma larga absorção, no meio acadêmico, tanto os maquinários tecnológicos quanto os jogos digitais precisam de novas percepções, visto que atualmente mais de 35 milhões de brasileiros, em sua maioria jovens, jogam os jogos eletrônicos em consoles e computadores, assim como tantos outros em celulares e tablets $^{2}$ e, concomitantemente, sentam-se em bancos escolares. Ou seja, a realidade, tanto a escolar como a não escolar, está amalgamada pela tecnologia.

Seguindo essa linha, neurocientistas, tais como Gary Small e Gigi Vorgan (2008 apud FROSI; SCHLEMMER, 2010), por intermédio de uma investigação intitulada de iBrain: Surviving the Technological Alteration of the Modern Mind, constataram que os cérebros dos jovens que estão crescendo absortos em novas tecnologias estão se tornando mais maleáveis e apresentando maior moldabilidade em relação às gerações anteriores, proporcionando melhoramentos nas áreas responsáveis pelo raciocínio complexo, pela tomada de decisões e pelos aspectos cognitivos.

Tomando os games como referência, Santaella (2013) corrobora com essas afirmações ao inferir que os jogos digitais têm elevado potencial no desenvolvimento de habilidades socioafetivas e cognitivas, que alavancadas pela motivação e pelos avanços exploratórios dos contextos, viabilizados pela força paidia-ludus (CAILLOIS, 1990), convertem-se em linguagens tonificantes da educação. Acerca dessas considerações, a pergunta-guia de nossa reflexão é: os jogos digitais, enquanto linguagens, podem ser parte do processo maior para pensar os temas geradores freireanos? Portanto, esse escrito teórico busca aproximar a tecnologia, com face voltada aos jogos digitais, à educação, por meio de reflexões vindas da filosofia, e da pedagogia de Paulo Freire. E ainda, em um diálogo introdutório com a teoria pragmática norte-americana, arriscaremos possíveis encontros e desencontros entre tais ideias, sempre levando em conta que os jovens da contemporaneidade possuem suas próprias linguagens e desenvolvem-se em uma 
3 Essa citação foi retirada do livro Pedagogia do Oprimido, na sua $50^{\mathrm{a}}$ edição. Embora Freire tenha alertado seu editor - a partir do livro Pedagogia da Esperança - que desejava que sua linguagem sexista e androcêntrica fosse corrigida no todo de sua obra, visto que acatava o que as feministas tinham o ensinado sobre o machismo e suas consequências, observamos que na $50^{\mathrm{a}}$ versão ainda estamos marcando passo na linguagem androcêntrica. Por esse motivo, tomamos a liberdade de alterar as palavras "homem" que se reafirmavam nessa passagem e em todas as passagens que citaremos de Paulo Freire ou de outros autores. Confira o verbete de Edla Eggert (2008), Homem/Mulher do Dicionário Paulo Freire, organizado por Danilo Streck, Redin, e Zitkosky. cultura tecnológica posterior à escola tradicional. Nesse sentido, compreendemos que a educação não pode fugir dos avanços tecnológicos, assim como também não pode concebê-los na qualidade de solução para todos os problemas, entretanto, deve cunhá-los como artefatos colaborativos a fins educacionais. Mas, quando se trata de tecnologia na educação, assumimos o que diz Paulo Freire (2013, p. 85): “[...] não a divinizo, de um lado, nem diabolizo de outro. Por isso mesmo, sempre estive em paz para lidar com ela”.

\section{A QUESTÃO DOS TEMAS GERADORES: POSSIBILIDADES E APROXIMAÇÕES}

Sem perder de vista a problemática que esquadrinhamos, podemos inferir que os temas geradores de Paulo Freire são o start para um processo cognitivo de construção da alfabetização pelo universo vocabular e contextual dos sujeitos da educação. Isto é, quem está no processo de aprender, e quem está no processo de ensinar. Para Freire (1980), alfabetizar é também conscientizar e isso, impreterivelmente, perpassa por uma aproximação crítica da realidade que todas as pessoas envolvidas estão circunscritas. E o que seria conscientização senão interagir com o mundo abertamente?

Cabe apontar que, para a filosofia semiótica de Charles Sanders Peirce (1974), somente é possível interagir com o universo mediante signos, esses constituídos e construídos de distintas linguagens - tais como: simbólicas, visuais, sonoras, táteis, sensoriais, etc. Todavia, muito mais que uma interação reativa, o universo signíco peirceano é um mundo aberto, mútuo e coparticipativo, tal como o universo dialógico de Freire, sendo esse, igualmente um transcurso de semiose ilimitada em que "[...] o eu se torna o outro e o novo outro, por sua vez, se torna eu novamente e assim por diante" (NÖTH, 1995, p. 75). Dizendo de outro modo, dialogar abertamente em um processo educativo é refletir a realidade pela via de um tema que incorpora um objeto cognoscível representado codificadamente e posteriormente descodificado, ocasionando, assim, um oceano de signos que possivelmente transbordarão em outros temas geradores açodados pelos aprendentes e ensinantes no mundo. Não é outra coisa, conforme menciona Freire: "[...] importante reenfatizar que o tema gerador não se encontra nas pessoas isoladas da realidade, tampouco na realidade separada delas. Só pode ser compreendido nas relações [seres humanos-seres humanos] humanos-mundo"3 (FREIRE, 2011, p. 136).

Como parte maior do método Paulo Freire, os temas geradores englobam todas as linguagens da realidade experiencial, inclusive a palavra - simbólica, no caso palavras geradoras -, pois "[...] procurar o tema gerador é procurar o pensamento de quem pensa sobre a realidade e a sua ação sobre esta realidade que está em sua práxis" (FREIRE, 1980, p. 32). Destarte, o tema gerador é o aspecto preambular 
do processo de construção cognitiva que culminará na alfabetização - por palavras geradoras - e na conscientização do sujeito sobre seu contexto, pois tanto o pensamento como a práxis apenas funcionam enquanto linguagens.

Linguagens essas que se transformam cotidianamente, ao passo que o ser humano, o mundo, a cultura e a natureza também se transformam. Linguagens que fundamentam também a educação que, fundida com a prática cultural, miscigena - no sentido de semiose - o mundo experiencial do conhecimento, assim como o mundo da vida - em nível epistemológico e o ontológico. Nesse sentido, a educação é permeada constantemente por linguagens advindas de todas as esferas da vida, tal e qual é linguagem que permeia todo o estrato de nossa vivencia.

Uma educação válida, em consonância com Paulo Freire (1980), deve estabelecer relações com o contexto da sociedade na qual o ser está radicado, precisando que os temas geradores sejam idealizados por intermédio do conjunto de pensamentos e ações que caracterizam o tempo atual. Portanto, buscar temas geradores em nosso tempo presente é confrontar-se, em certa medida, com a linguagem ubíqua permeada pela cultura ciber, visto que são essas linguagens que constituem parte dos valores, das ideias e dos obstáculos da atualidade.

À vista disso, as tecnologias - incluindo os jogos digitais - não só representam a concretude das ideias e valores em voga na sociedade atual, como, quando não compreendidas adequadamente, também acabam por se tornar óbices aos indivíduos privados e não instruídos no acesso/na leitura a essas linguagens, fator que impede a criticidade dos sujeitos perante seu agir no mundo tecnológico ocidental. Esse "barramento", segundo o Indicador de Analfabetismo Funcional (INAF) do Instituto Paulo Montenegro (2015), afeta grande parte da população brasileira, especialmente no concernente à alfabetização tecnológica, terminando em uma espécie de inclusão-exclusão, geratriz de seres humanos oprimidos.

Seres humanos sem alfabetização tecnológica em um tempo como o nosso, são seres humanos mais propensos à manipulação. São alvos fáceis para uma educação bancária, preconizada pela grande mídia e pelas grandes corporações. Em nosso tempo, a questão que mostrará o norte à libertação vai além da palavra escrita, pois as tecnologias ubíquas requerem leitores atentos às distintas linguagens advindas desses aparatos, uma alfabetização calcada tanto nos símbolos quando nos ícones e nos índices - no sentido peirceano dos termos. $\mathrm{O}$ mundo atual requer mais do que nunca a educação orgânica pensada por Freire ainda nos anos 1950, período referente à industrialização do Brasil. Para Paulo Freire, "[...] a organicidade do processo educativo implica a sua integração com as condições do tempo e do espaço a que se aplica para que possa alterar ou mudar essas mesmas condições. Sem esta integração o processo se faz inorgânico, superposto e inoperante" (FREIRE, 2003, p. 11). 
De acordo com pesquisa recente do Comitê Gestor da Internet no Brasil (CGI), apenas $7 \%$ dos acessos às tecnologias digitais e a seus corolários, tais como internet, games e vídeos etc., ocorrem na escola, sendo os outros $93 \%$ feitos em casa, no telefone celular, tablets ou na casa de amigos (CRUZ, 2014). Em outras palavras, a educação "tecnológica” hoje é muito mais não escolar do que escolar. Porém, isso significa que a educação escolar fica isenta de responsabilidades?

O papel central da educação e do educador escolar, nesse contexto, está em articular ações através de reflexões, para refletir os resultados alcançados por essas ações - ad infinitum. Isto é, pensar a educação nas escolas atuais, com vistas ao mundo tecnológico e ao pensamento freireano, é retornar, em certa medida, a máxima pragmática proposta por William James (1979, p. 17-18), a saber, “[...] tentar interpretar cada noção traçando suas consequências práticas". Assim, o que cabe à educação escolar e a quem educa, em coparticipação com a educação orgânica, é pensar conjuntamente com todas as pessoas envolvidas no processo de ensino e aprendizagem, suas ações enquanto práxis do ser humano no mundo -, codificando-as em linguagens próximas/relacionais à sua vivência, para posteriormente descodificá-las crítica e reflexivamente, instituindo novas ações. Esses princípios fundamentam o que já delineamos e o que Paulo Freire denominou de temas geradores. Ou seja, estamos propondo uma "atualização" do método Paulo Freire pelas vias dos jogos digitais. E nos ancoramos em Álvaro Vieira Pinto, autor que reconhece a importância da proposta freireana, ou melhor, que foi um dos motivadores para que Freire aprofundasse seus caminhos em direção a uma educação libertadora. E, nesse sentido, Vieira Pinto foi mais além, principalmente ao inferir que sem acesso "[...] ao código 'elaborado', semântica e sintaticamente mais complexo, falado por pessoas da classe alta, os indivíduos da classe baixa jamais terão condições cognitivas para pensar de modo totalizante, refletindo sobre os fatores responsáveis pela injustiça e a desigualdade" (VIEIRA PINTO, 1960, p. 191). Não obstante, Vieira Pinto entendia que: "Os métodos bem-sucedidos, como o de Paulo Freire, podem acabar se tornando um quisto, uma coisa que impede o prosseguimento do seu próprio desenvolvimento" (VIEIRA PINTO, 1987, p. 46, grifos nossos). Diante dessas inferências, percebemos o que isso significa, pois Vieira Pinto (1987) reforça que o entendimento do método Paulo Freire não deve cristalizar-se nas formas iniciais, mas estar sempre em constante revisão e atualização, pois é somente pelo acesso às mais altas linguagens da sociedade coetânea que os sujeitos se desenvolvem. Sendo as tecnologias uma das linguagens mais complexas utilizadas pela "elite" em nossos dias, porque privar os indivíduos do processo educativo dessas linguagens? Porque não alfabetizá-los para conscientizarem-se das manipulações efetuadas por essas vias? Porque não utilizar o método Paulo Freire e os temas 
4 Os jogos digitais, se forjados - apenas como elementos codificadores, podem ser extremamente eficientes, visto que conjugam as três matrizes da linguagem. Nas palavras de Freire: "Uma codificação pode ser simples ou composta. No primeiro caso, pode-se usar o canal visual, pictório ou gráfico, o tátil ou o canal auditivo. No segundo, a multiplicidade de canais" (FREIRE, 2011, p. 162). geradores nessa perspectiva? A seguir, passamos a apresentar uma proposta de aproximação entre esses temas geradores e os jogos digitais.

\section{JOGOS DIGITAIS E TEMAS GERADORES: POSSIBILIDADES PARA A EDUCAÇÃO}

Seguindo os argumentos, bem como a ideia de que os temas geradores podem compilar todas as linguagens refletidas no processo educativo, proporcionando a todas as pessoas envolvidas, tanto estudantes quanto docentes, a conscientização da práxis no mundo aliando a alfabetização à sociedade coetânea, a atribuição fulcral da educação escolar, conforme citamos, é incentivar e principiar a reflexão dos sujeitos pelos temas geradores no concernente às tecnologias que os colocam em ação com a realidade, bem como alicerçam a educação não escolar. Nesse sentido, as tecnologias podem ser os temas geradores, assim como podem codificar temas geradores. Partindo desses pressupostos e das ideias de Gros (2003), compreendemos que esses temas geradores podem ser pensados a partir dos jogos digitais, pois estes se encontram entre as principais formas de linguagens codificadas na atualidade em convívio direto com temáticas de nosso mundo, carecendo de descodificações, que podem ser proporcionadas pela educação, tendo por finalidade rumar os sujeitos à conscientização.

No entanto, partimos da hipótese de que a maioria dos estudantes em suas casas, lan houses e smartphones, não jogam videogames pedagógicos, visto que esses carecem de linguagens importantes, tais como: ficcionalidade, hibridez, interação, imersão, regras, imprevisibilidade, que influenciam diretamente na escolha do game pelo jogador/ jogadora. Assim, apresentamos quadro com alguns jogos digitais voltados ao entretenimento, que podem ser cunhados tanto como elementos codificadores das temáticas quanto transformarem-se em temas geradores, oferecendo a partir de (re)codificações e descodificações possibilidades de desvelamentos críticos sobre as ações, gerais ou pessoais, além de viabilizar novos temas geradores ${ }^{4}$. Examinemos o quadro a seguir. 
Quadro 1 - Quadro de Jogos Digitais que podem ser usados no processo educativo escolar ou não escolar

\begin{tabular}{|c|c|}
\hline Jogo & Tema \\
\hline Age of Empires & História \\
\hline Aspirin Trivia Game & Educação Econômica \\
\hline Asterix e o desafio de César & Geografia e história \\
\hline Big Brain Academy & Raciocínio e Memória \\
\hline Call of Duty & História \\
\hline City Rain & Administração de cidades e sustentabilidade \\
\hline Civilization & História \\
\hline Dreambox & Matemática \\
\hline Globetrotrotter XL & Geografia \\
\hline Greenpeace WeAtheR & Meio ambiente e Ecologia \\
\hline Guitar Hero & Música \\
\hline I Love Traffic & Educação no trânsito \\
\hline Xbox - Just Dance & Dança \\
\hline Lanfill Bill & Reciclagem \\
\hline Light-Bot & Lógica e Programação \\
\hline Lury of the Labyrinth & Álgebra \\
\hline My Japonese/English/Português Coach & Línguas \\
\hline Objection! & Certificação e Educação continuada \\
\hline Phoenix Wrigth: Ace Attorney & Direito \\
\hline Phsysicus & Física \\
\hline Pro Evolution Soccer & Futebol - Tática \\
\hline Rock Band & Música \\
\hline Sim City & Administração de cidades \\
\hline Sim Healt & Criação de política públicas/Alimentação \\
\hline Spore & Biologia \\
\hline The Battle of the Brains & Diversidade \\
\hline Valkyrie Profile & Mitologia Nórdica \\
\hline Wii Sport's & Regras esportivas - Boxe, Tênis, Ping-pong, Beisebol, Golf. \\
\hline Wii Fitness & Exercícios físicos e Yoga \\
\hline
\end{tabular}

Fonte: Adaptado de Mattar (2010); Frosi e Schelmmer (2010).

Acreditamos que, a partir das primeiras experiências com as descodificações viabilizadas pelos games, os estudantes-docentes vão aos poucos criando mapas conceituais críticos que permitirão autonomia na (re)codificação, descodificação e até mesmo propostas de temas geradores a partir de outros jogos digitais ou de outras atividades de

5 Segundo o Projeto Memória, Paulo Freire considera que "[...] as mulheres e os homens como corpos conscientes sabem bem ou mal de seus condicionamentos e de sua liberdade. Assim encontram, em suas vidas pessoal e social, obstáculos, barreiras quaisquer que precisam ser vencidas. A essas barreiras [...] chama de 'situações-limite". Disponível em: <http://www.projetomemoria.art.br/PauloFreire/paulo_freire_hoje/o4_pf_hoje_ reinventando_pf.html>.

6 Uma versão simples do jogo está disponível em: <http://www.clickjogos.com.br/Jogos-online/Acao-e-Aventura/I-Love-Traffic/>. suas vivências. Desse modo, complementarão experiências escolares em ambientes não escolares, os quais serão muitas vezes ubíquos, subvertendo o tempo-espaço linear da educação escolar. Vejamos um exemplo de aplicação na educação escolar: partindo de uma "situação limite" ${ }_{5}$ observada através de diálogo entre as pessoas, por exemplo, o elevado índice de mortes no trânsito, o docente-estudante propõe como tema gerador a imprudência e o desrespeito às sinalizações de trânsito pelos motoristas brasileiros, codificando-o por meio do game I Love Traffic ${ }^{6}$, no qual os estudantes-docentes e os docentes-estudantes mediatizarão situações de tráfego “concretas”, tanto ao planejá-las 
7 Um gameplay pode ser visualizado neste link: <https://www.youtube.com/watch?v= SQpcngDegR8>. quanto ao respeitar o planejamento de outrem para, posteriormente, refletirem aberta e criticamente o objeto cognoscível - que pode ser a ação, em alguns casos, real dos sujeitos do processo educativo. Contudo, Frosi e Schlemmer (2010) propõem que, mesmo atividades como esta, para colherem resultados positivos, dependem de como o processo educativo será esboçado, articulado e desenvolvido, cabendo ao/à docente-estudante constante revisão de sua prática, especialmente em tempos multifacetados de leitores e tecnologias ubíquas.

Não obstante, os jogos digitais oferecem ainda à educação inúmeras possibilidades para incrementar a motivação, a cognição, a interação e a interdisciplinaridade. Segundo Santaella (2013), os vastos estímulos proporcionados pelos videogames durante o ato de jogar corroboram para tornar sujeitos mais espertos na resolução de problemas, motivar a curiosidade a partir de experiências cotidianas sobre o conteúdo escolar, assim como proporcionar o desenvolvimento de aprendizagens corporificadas e situadas, facilitando o pensamento criativo - no sentido peirceano do termo. O trabalho crítico em grupo e a capacidade de reestruturar e reconfigurar o conhecimento é outro ponto importante, de modo a ver os problemas de múltiplas faces. A autora atesta esta percepção ao enfatizar que "[...] os games estão estruturados de modo a encorajarem a aprendizagem não passiva por meio do seu design e dos domínios da semiótica, que incentivam o jogador a compreender e estabelecer inter-relações entre os signos, estimulando a reflexão, a apropriação de significados, o autoconhecimento e o desenvolvimento de competências" (SANTAELLA, 2013, p. 258).

Nesse sentido, autores como Santaella (2009, 2013) e Poltrunieri (2009) defendem que os jogos digitais não só são objetos de estudos interdisciplinares, como possibilitam a interdisciplinaridade na educação pela hibridez das linguagens. Esse autor os compara à obra de arte Parangolé, de Hélio Oiticica; afinal, para o autor, além de serem trabalhos igualmente compostos por linguagens hibridas, os games, tal como a obra do artista brasileiro, atuam enquanto "[...] ponte que possibilita ao ser humano realizar uma permeação constante entre as áreas do saber e os repertórios individuais" (POLTRUNIERI, 2009, p. 164). Nos jogos digitais, a conexão acontece tanto epistemologicamente quanto ontologicamente, da educação escolar à educação não escolar e vice-versa.

Um bom exemplo está no jogo para Nintendo Wii My English Coach ${ }^{7}$. Este game - voltado para o entretenimento, porém, muito utilizado na educação escolar, como cursos de inglês - oferece aos jogadores treinamentos gramaticais e fonéticos em diversos níveis de desafios. Conjuntamente com as palavras simbólicas, emergem durante a ação ícones e índices relacionados à temática, que têm por intuito complementar o "mundo" da palavra estudada. Em uma aula de primeira série do ensino básico, o 
8 Esta relação faz com que o nosso "corpo se sinta bem" injetando endorfina em nosso sistema físico, relacionando, mesmo que inconscientemente, $\mathrm{o}$ ato educativo a boas sensações (KOSTER, 2004; FROSI; SCHLEMMER, 2010). docente-estudante pode propor aos estudantes-docentes a atividade mediada pelo videogame, tendo cada estudante-docente uma jogada para resolver o desafio proposto. Após as explicações introdutórias, o jogo se inicia. Na tela, aparece o ícone de uma maçã, na lista de palavras em inglês está: a) Apple; b) Aple; c) Epple; d) Eipool. E, após o acerto ou erro por parte da jogadora ou do jogador, a palavra correta conjuntamente com sua pronúncia é apresentada para a turma. Aliado a isso, o docente-estudante faz emergir por intermédio de explicações as qualidades biológicas - família, ordem, propriedades vitamínicas, etc. -; a história na mitologia, os países que mais produzem e suas regiões, aspectos culturais e até mesmo aproximação com a física de Isaac Newton. Ou seja, uma atividade assim retoma a proposta dos temas geradores, visto que o "[...] importante não é transmitir conteúdos específicos, mas despertar uma nova forma de relação com a experiência vivida" (FECAM, 2016).

Nessa direção, concordamos com Frosi e Schlemmer (2010), principalmente ao inferir que, quando usados adequadamente e em conexão com os conteúdos do processo educativo, os jogos digitais transformam-se em importantes agentes do aprender, pois além de oportunizar a interdisciplinaridade, propiciam o vínculo da aprendizagem ao prazer$^{8}$. No entanto, se os jogos digitais oferecem à educação novas possibilidades em seu agir, seja por intermédio de codificações de temas geradores que resultarão em reflexões críticas sobre assuntos atuais, seja pelo início da alfabetização tecnológica, a educação em seu papel central de emancipadora, deve atentar para o que Adorno (1995) propõe, isto é, estar sempre comprometida com a formação de pessoas críticas, viabilizando a conscientização dos malefícios de uma vida reduzida a mecanicidade e aos louros da indústria cultural, extremamente presente no "planeta games".

Contudo, uma coisa fica explícita: as tecnologias, os jogos digitais e a educação se intercruzam em múltiplos pontos desta "teoria de cordas", confeccionando um tempo-espaço-lugar geral, mas também espaços, lugares e tempos quânticos. Assim como não existe atualmente educação sem a escola, também não existe educação sem os distintos momentos e aparatos do "mundo da vida". A educação para o mundo contemporâneo, ao mesmo tempo em que Ubíquo Contemplativo, requer um projeto orgânico, voltado para nosso povo e trilhado por inúmeras rotas sem fim. Nesse sentido, pensar os jogos digitais como temas geradores não somente faz sentido como também aponta o sentido para sujeitos que interagem cotidianamente com tais máquinas.

\section{PARA CONCLUIR}

Apesar de uma história relativamente curta, os jogos digitais são hoje a principal ferramenta de acesso dos 
jovens ao mundo tecnológico (GROS, 2003). Conforme mencionamos, estima-se que mais de 35 milhões de pessoas no Brasil, em sua maioria jovens, jogam ou já jogaram um videogame. Tal fato - um dos muitos que circulam estes aparatos -, demonstra a urgência de pensá-los em novos modelos de utilização, bem como de incorporá-los definitivamente ao processo educativo.

Ao visar um outro modelo, nossa proposta neste ensaio, portanto, foi de cunhá-los e, em boa medida, teorizá-los enquanto linguagens que corroboram com o ideal de educação freireana. E, mais especificamente como parte dos temas geradores, visto que, conforme nos alerta Freire (1980), “[...] procurar o tema gerador é procurar o pensamento do ser humano sobre a realidade e a sua ação sobre esta realidade que está em sua práxis”. Explicando de outro modo, ao forjar os jogos digitais como codificadores e/ou decodificadores de temas geradores, ou até mesmo como temas geradores, esses aparatos possibilitarão uma primeira aproximação e experiência crítica com as tecnologias, logo, com a realidade - conforme exemplos abordados. Não só isso, a partir das primeiras experiências com as descodificações viabilizadas pelos games, os estudantes-docentes vão aos poucos criando mapas conceituais críticos que permitirão autonomia na (re)codificação, descodificação e até mesmo propostas de temas geradores.

Do nosso ponto de vista, isso é circunstancial em nosso tempo, especialmente em função da guerra ideológica que circula nos meios digitais. Nessa direção, compartilhamos das ideias de Freire, pois acreditamos que a função da educação orgânica é preparar as pessoas para serem protagonistas frente ao mundo contemporâneo. Assim, fica claro para nós que a educação deve formar pessoas aptas a ler e interpretar mensagens nos mais diversos meios, sejam estes ubíquos ou contemplativos, pois, conforme dados do INAF, ainda somos um país de analfabetos funcionais, consequentemente dóceis à educação bancária, subjugadora.

Se educação é mudança de realidade, é necessário um amplo processo de alfabetização que inclui os aparatos tecnológicos. Esses não só representam parte da concretude das ideias e valores em voga na contemporaneidade, mas quando não entendidos devidamente, acabam por obstruir o desenvolvimento crítico dos indivíduos no mundo tecnológico. Portanto, ficou explícito para nós que a educação escolar, não pode fugir desse chamamento e os jogos digitais podem ser uma boa provocação nesse intercruzamento cognocente.

\section{REFERÊNCIAS}

ADORNO, Theodor, W. Educação após Auschwitz. In: ADORNO, Theodor, W. Educação e Emancipação. Rio de Janeiro: Paz e Terra, 1995. p.119-138. 
ARMOR GAMES. I Love Traffic. Disponível em: <http:// www.clickjogos.com.br/Jogos-online/Acao-e-Aventura/I-Love-Traffic/>. Acesso em: 10 de jun. 2015.

ARRUDA, Eucidio Pimenta. Jogos digitais e aprendizagens: $O$ jogo Age of Empires III desenvolve ideias e raciocínios históricos de jovens jogadores? 2009. 238 f. Tese (Doutorado em Educação) - Programa de Pós-Graduação em Educação, Universidade Federal de Minas Gerais, Belo Horizonte, 2009.

ARRUDA, Eucidio Pimenta. Fundamentos para o desenvolvimento de Jogos Digitais. Porto Alegre: Bookman, 2014.

BERLITZ. My english coach. 27 ago. 2009. 1 post (2 min 21 s.). Disponível em: <https://www.youtube.com/ watch?v=SQpcngDegR8>. Acesso em: 8 jul. 2015.

CAILLOIS, Roger. Os jogos e os homens. Lisboa: Cotovia, 1990.

CRUZ, Fernanda. O uso da internet nas escolas públicas cresce, mas conexão ainda é lenta. Disponível em: <http://www.ebc.com.br/tecnologia/2014/o7/uso-da-internet-nas-escolas-publicas-cresce-mas-conexao-ainda-e-lenta>. Acesso em: 4 fev. 2016.

EGGERT, Edla. MULHER/HOMEM (Relação de gênero, relações dignas). In: STRECK, Danilo; REDIN, Euclides; ZITKOSKY, Jaime José (Org.). Dicionário Paulo Freire. São Paulo: Editora Autentica, 2008. p.281.

FECAM. Paulo Freire e os temas geradores. Disponível em: <http://eventos.fecam.org.br/arquivosbd/paginas/1/o.667326001366389749_paulo_freire_e_os_temas_geradores.pdf $>$. Acesso em: 10 mar. 2016.

FREIRE, Paulo. Conscientização. São Paulo: Moraes, 1980.

FREIRE, Paulo. Educação e Atualidade Brasileira. São Paulo: Cortez, 2003.

FREIRE, Paulo. Pedagogia do Oprimido. 50. ed. Rio de Janeiro: Paz e Terra, 2011.

FREIRE, Paulo. Pedagogia da autonomia: saberes necessários à prática educativa. 46. ed. Rio de Janeiro: Paz e Terra, 2013.

FROSI; Felipe O.; SCHLEMMER, Eliane. Jogos Digitais no contexto escolar: desafios e possibilidades para a prática docente. In: IX SB GAMES, 9., Florianópolis, 8-10 de nov. 2010. Anais... Florianópolis, 2010. p. 115-122. Disponível 
em: <http://www.sbgames.org/papers/sbgames10/culture/full/full13.pdf > . Acesso em: 14 maio 2014.

GAMEFAQS. My english coach. Disponível em: <http:// www.gamefaqs.com/ds/955858-my-english-coach-para-hispanoparlantes/images $>$. Acesso em: 8 jul. 2015.

GROS, Begoña. The impacto of digital games in education. First Monday, v. 8, n. 7, jul. 2003. Disponível em: <https://www.mackenty.org/images/uploads/impact_of_games_in_education.pdf.> Acesso em: 10 jan. 2016.

GULARTE, Daniel. Jogos Eletrônicos: 50 anos de interação e diversão. Teresópolis: Novas Ideias, 2010.

INSTITUTO PAULO MONTENEGRO. Indicador Brasileiro de alfabetismo funcional. Disponível em: <http://www.observatoriodopne.org.br/metas-pne/9-alfabetizacao-educacao-jovens-adultos/estrategias/9-11-capacitacao-tecnologica-para-inclusao-social-e-produtiva/saiba-mais/inaf-indicador-de-alfabetismo-funcional $>$. Acesso em: 2 maio 2015.

JAMES, Willian. Pragmatismo. São Paulo: Abril, 1979.

KOSTER, Raph. A theory of fun for game design. Phoenix: Paraglyph Press, 2004.

MATTAR, João. Games em Educação. Como os nativos digitais aprendem. São Paulo: Pearson, 2010.

NÖTH, Winfried. Panorama da Semiótica: De Platão a Peirce. São Paulo: Annablume, 1995.

OLHAR DIGITAL. Brasil é o quarto país com mais jogadores de videogame. 2 maio 2011. Disponível em: <http://olhardigital.uol.com.br/games-e-consoles/noticia/brasil_e_4_pais_com_mais_jogadores_de_videogame/17753>. Acesso em: 10 mar. 2014.

PEIRCE, Charles Sanders. Semiótica e Filosofia. São Paulo: Editora Cultrix, 1974.

POLTRUNIERI, Fabrizio. O jogo do Parangolé. In: SANTAELLA, Lucia; FEITOSA, Mirna (Org). Mapa do jogo. São Paulo: Cengage Learming, 2009. p.166-179.

PROJETO MEMÓRIA. Reinventando Paulo Freire o inédito viável. Disponível em: <http://www.projetomemoria.art.br/PauloFreire/paulo_freire_hoje/o4_pf_ hoje_reinventando_pf.html>. Acesso em: 12 fev. 2015.

SMALL, Gary; VORGAN, Gigi; COLLINS, Harper. iBrain: Surviving the technological alteration of the modern mind. New York: Harper Collins, 2008. 
SANTAELLA, Lucia. O paroxismo da auto-referencialidade nos games. In: SANTAELLA, Lucia; FEITOSA, Mirna (Org.). Mapa do jogo. São Paulo: Cengage Learming, 2009. p.51-66.

SANTAELLA, Lucia. Comunicação Ubíqua: repercussões na cultura e na educação. São Paulo: Paulus, 2013.

TEIXEIRA, Coelho. O que é industrial cultural? São Paulo: Brasiliense, 2007.

VIEIRA PINTO, Álvaro. Consciência e Realidade Nacional: A Consciência Ingênua. Rio de Janeiro, ISEB, 1960.

VIEIRA PINTO, Álvaro. Sete lições sobre educação de adultos. São Paulo: Cortez Editora, 1987.

VIEIRA PINTO, Álvaro. O Conceito de Tecnologia, v. 1. Rio de Janeiro: Contraponto, 2005a.

VIEIRA PINTO, Álvaro. O Conceito de Tecnologia, v. 2. Rio de Janeiro: Contraponto, 2005b.

Recebido em: 13/08/2016

Aprovado em: 30/11/2016 